\title{
Proactive Learning Culture: Practical Learning and Experience from Research into Senior Projects
}

\author{
Wongpanya Nuankaew, Sittichai Bussaman, Direk Teeraputon, and Pratya Nuankaew
}

\begin{abstract}
Senior projects allow students to move the learning process from basic knowledge to an interdisciplinary approach. The purpose of the research is to survey the attitude and perception as collaboration between researchers and students to develop a clustering model for advisors and students and to develop factors that are significant to predict the right match in the senior projects course. Data collection was with a questionnaire consisting of $\mathbf{4 6 3}$ samples from 7 administrators, 68 lecturers, 26 staff and 362 students from two universities: The Rajabhat Mahasarakham University, and the University of Phayao. The research methodology is designed and divided into three sections: preparation, implementation, and conclusion. The result shows that the satisfaction and the overall acceptance level were at a high level $($ mean $=4.04$, S.D. $=0.88)$. Moreover, the developed model has the highest level of efficiency (accuracy $=98.06 \%$ ). For future research projects, the researchers are committed on the development of learners' achievement and aims to promote a learning culture based on the results of this research, and active learning of educational institutions.
\end{abstract}

Index Terms-Educational engineering, educational data mining, proactive learning culture, lifelong learning, learning modeling.

\section{INTRODUCTION}

In the world of learning and educational theory, developing learners to understand research problems and conceptualizing the development of thought processes are highly difficult and complicated to do. In addition, creating a learning culture that promotes critical and analytical thinking [1] needs to be concrete in order for learners to understand the process of the problem and coming up with a solution.

According to the intentions of the curriculum for modern education [2]-[4], the role of instructors and learners have changed into becoming classroom colleagues, which require both to understand and cooperate together on finding answers to a question. The instructor is not responsible for educating the learner anymore. The instructor acts as a coach that guides learners to perform well in their academic discipline. At the same time, the learner needs to solve a specific problem in the task assignment. It seems that students must

Manuscript received May 17, 2020; revised December 21, 2020.

Wongpanya Nuankaew is with the Faculty of Information Technology, Rajabhat Mahasarakham University, Maha Sarakham, 44000, Thailand (e-mail: wongpanya.nu@rmu.ac.th).

Sittichai Bussaman is with the Faculty of Science and Technology, Rajabhat Mahasarakham University, Maha Sarakham, 44000, Thailand (e-mail: sittichai.bus@gmail.com).

Direk Teeraputon is with the University of Phayao, Phayao, 56000, Thailand (e-mail: direk.te@up.ac.th).

Pratya Nuankaew is with the School of Information and Communication Technology, University of Phayao, Phayao, 56000, Thailand (corresponding author; e-mail: pratya.nu@up.ac.th). find a solution to the research problem for the purpose of understanding the thought process and knowledge for themselves.

For research experience, one of the main problems of the research process is to develop the research findings into a practical tool and applications [5]. Because most researchers in the university need to perform the teaching tasks, they spend most of their time preparing and summarizing the teaching and learning outline for the students. They also need more time to evaluate each learners' outcome. Meanwhile, this corresponds to the problem of undergraduate students who wish to perform a senior project, but want something different, innovative and ideally practical with their social environment. For this reason, the author has made a pilot project to solve the problem, which is demonstrated in Fig. 1 and Fig. 2.

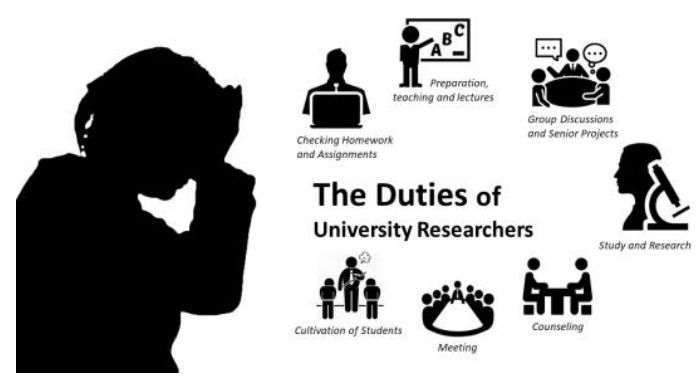

Fig. 1. The duties of university researchers.

Fig. 1 provides an overview and source of the problem on "why the author brings the results of the research", and forward it to students for developing the senior project, as shown in Fig. 2 below.

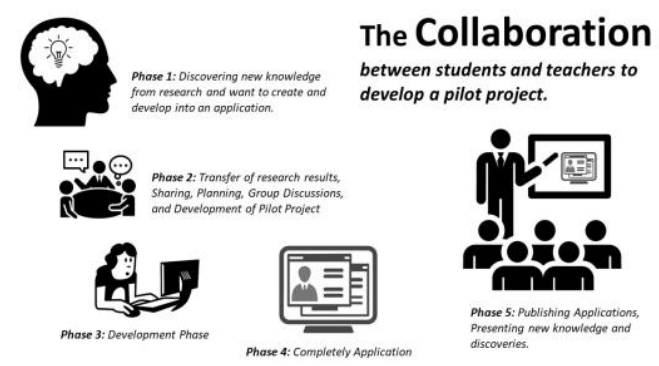

Fig. 2. Pilot project development.

Based on the results of a pilot project, the author has achieved the objective of implementing it as a high level, where students in the pilot project can create applications and submit them to the national conferences [6], [7]. An overview of past to present operations is shown in Fig. 3.

Fig. 3 illustrates the accomplishments of learners and collaborators who work together in attracting the attention of 
current students, administrator, researchers and colleagues in the organization to join the project. Moreover, the major goal of the research team is to develop a learner's culture to create a proactive learning culture in educational institutions, which is planned for future research.

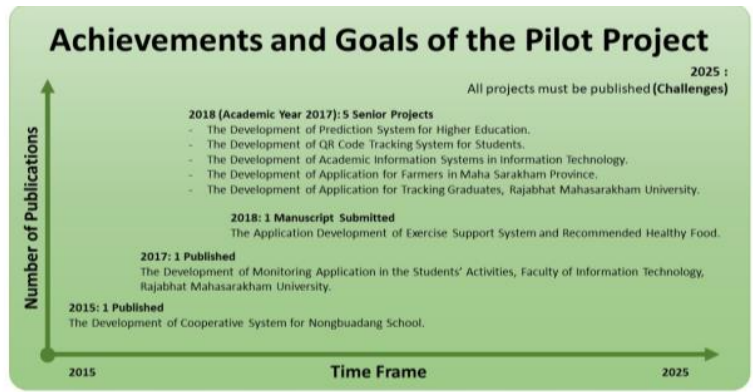

Fig. 3. The challenge of developing a culture of aggressive learning.

The paper's outline consists of five parts: a summary of the relevant research in Section II, data collection and research methodology are presented in Section III, and research results and discussion reports are provided in Section IV. Finally, the conclusion is summarized in Section V.

\section{LITERATURE REVIEWS}

\section{A. Proactive Learning}

Proactive learning or active learning is an essential feature of a person in a learning society that is aware of and responds to many events and stimuli. Having a proactive feature will allow the person to behave appropriately and produce good results. Examples of proactive learning promotion include Zampunieris's research [8] which introduces an electronic learning management system called "proactive LMS". These e-Learning platforms are designed to improve the online interaction of users by taking appropriate action by the LMS itself. Ruiz-Iniesta's team [9] provided the proactive guidance approach for the storage of learning objects, which adapts to the student profile. Gallego's team [10] declared the proactive learning model named "Virtual Science Hub (ViSH)".

Proactive learning is not only for learner development but also being used as development withing an industry. For example, Reuter et al. [11] has demonstrated the application of proactive learning in employee's behavior. Moon and Carbonell [12] offered a way to evaluate labels and choose them based on proactive learning. It can be concluded that the adoption of proactive learning is available to all organizations.

\section{B. Cooperative Learning}

Cooperative learning model is one of the learning styles that aims to communicate and collaborate with both parties on academic achievements. For example, Tan and his colleagues [13] presented the model as eL-PCDA for management in e-Learning, based on learner's behavioral and environment of learning activities for cooperative learning. Vidhate and Kulkarni [14] claimed that their research can be applied the multi-agent system (MAS) to handle the performance enhancement of cooperative learning Meanwhile, Chang's teams designed the multi-user streaming feedback system for a cooperative learning application [15]. Chang's results shown that it improves the learners' interest and efficiency in learning.

Of all three examples, the demonstration of cooperative learning can be a learning achievement, which is important to include goals that both parties can emphasize on.

\section{Practical Learning}

Practical learning is a way of learning from experience. Because work is more problematic than problem solving, it requires more than opening the textbook. It's important for learners to find a way to solve the problem appropriately. However, practical learning is not just a matter of practice, it must be correct and reasonable, which become useful and applicable for the person performing with the theory.

Examples of success include the work done by Maresca $e t$ al. [16] which presented a collaborative teaching model used in the practical classroom of manufacturing engineering. Bouabid et al. [17] exposed how this practical learning approach can be extended to satisfy additional requirements. Mathew et al. [18] offered an application that promotes practical learning called "PROJECT HAWK", which draws on the learners' attention and changing their attitude towards seeking to comprehend more on the subject matter. Smith and Bluck [19] delivered a remote collaborative group in practical learning domains by using computer-based operating systems.

From the example, it is evident that learning from practice requires the use of knowledge and experience, which will help develop learners' viewpoint towards the importance of having a learning goal.

\section{RESEARCH Methodology}

The research methodology is designed and shown in Fig. 4.

\section{Research Methodology and Scope}

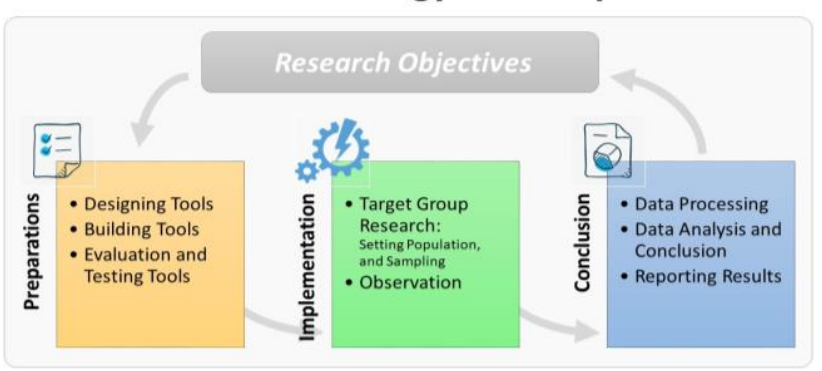

Fig. 4. Research methodology and scope.

\section{A. Research Objectives}

The purpose of the research is to take a survey on the attitude and perception of the collaboration between researchers and students to develop a clustering model for advisors and students, and to develop factors that are significant for predicting the right match in the senior projects course.

\section{B. Research Preparations}

\section{1) Designing tools}

At the stage of designing tools, the researchers conducted a 
preliminary study of the research process used for finding attitudes and satisfaction, which found that the appropriate and interesting tool for data collection was the questionnaire. At the same time, the data used in the analysis and design of the questionnaire were used by interviewers, including researchers who had received research grants, students who presented and published research papers, and executives who took part in the study.

\section{2) Building tools}

In the process of building tools, the questionnaire was designed into three parts. Part 1: General information of the respondents, Part 2: Satisfaction and Attitude Towards Pilot Projects, and Part 3: Suggestions for Pilot Projects. The main topic of part 2 is shown in Table I.

TABLE I: ISSUES AND ESSENCE ON PILOT PROJECTS

\begin{tabular}{ll} 
Main Essence & Dimensions Related to Essence: Sub-Stages \\
\hline 1. Organization & $\begin{array}{l}\text { 1.1 The policies of the organization } \\
\text { 1.2 The vision of the organization } \\
\text { 1.3 The mission of the organization } \\
\text { 1.4 Management and support of the organization }\end{array}$ \\
& 2.1 Experience and achievements of researchers \\
2. Researcher & 2.2 Aptitude and expertise of researchers \\
& 3.1 Knowledge and ability of learners \\
3. Students & 3.2 Interest in the research topics \\
& 4.1 Impressions and examples in the past \\
& 4.2 Staff support \\
4. Project Support & \\
&
\end{tabular}

The essence of Part 2 is to find out the level of opinion and attitude on the factors that encourage learners and teachers to collaborate on the research, which is comprised of four main areas: organization, researcher, students and project support.

3) Review stage

After designing and constructing the tool, it was tested for confidence and accuracy by three experts from the Department of Information Technology, Faculty of Information Technology, Rajabhat Mahasarakham University, Thailand.

\section{Evaluation and Testing Tools}

The research actions were divided into two phases: 1) Target group research, which described and defined the data collection scope, 2) Research observation, which shows the process of conducting research and gathering data.

\section{1) Target group research}

\section{a) Population}

Data gathering is done in all dimensions, which was limited to the area from two institutions: The Rajabhat Mahasarakham University, and the University of Phayao. The population is defined by four groups: administrators, lecturer, staff and students.

\section{b) Sampling}

Sampling is randomly selected from 463 samples, which were divided into four groups: 7 administrators, 68 lecturers, 26 staff and 362 students.

\section{2) Research observation}

a) Responding to the objectives

After completing the data collection, the data sets were already considered for whether the information provided covers the purpose of the research or had some limitation in validity.

\section{b) Meet the research framework}

The data set responds to the research based on the research framework and is used to test the hypothesis in its entirety.

c) Proceed with caution

In gathering information, the work will only attract the attention of the respondents and collect the data based on reality according to the actual situation.

\section{Research Conclusion}

At this stage, the selected instrument used for data analysis consisted of two parts: 1) basic statistical analysis including standard deviation (S.D.) and mean. 2) machine learning tools and data mining techniques, which consist of three parts:

\section{1) K-means}

The k-means is the most common algorithm used as an iterative refinement technique. It is also called Lloyd's algorithm [20], especially in the computer science community. The k-mean algorithm is performed by switching between two steps: 1) the assignment step, which assigns each observation to the cluster with the closest mean. 2) updates the procedure which is calculated by the new means to be a centroid of observations in a cluster.

\section{2) Decision tree}

The decision tree is one of the learning methods used in statistics, machine learning, and data mining. It works by determining data from observations and separating data for use in data consideration and finding predictive results. The benefit is getting important factors, which are caused by the nodes or the decision-making part of the model [21]-[23].

\section{3) Model performance}

The goal of the model performance is to assess the results and review the process [21]-[23]. The tools are used in the research, including cross-validation methods as shown in Fig. 5. Confusion matrix is mentioned in Fig. 6.

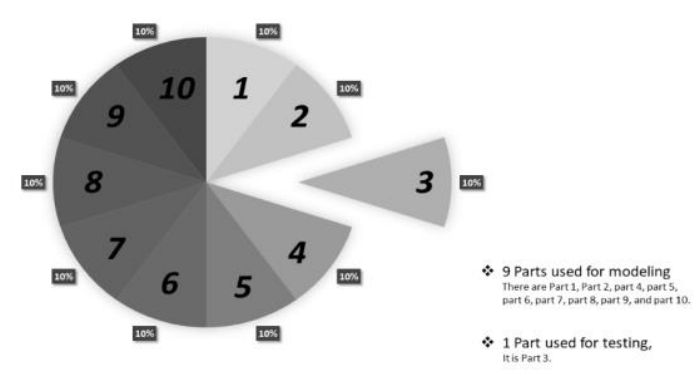

Fig. 5. Cross-validation methods.

Fig. 5 displays the separation of data for evaluating the model. The cross-validation method divides the data into two parts. The first part is used for modeling and the remainder is to test the model. In addition, model evaluation requires a tool called a confusion matrix [2] to test the model's 
performance; the principles are shown in Fig. 6.

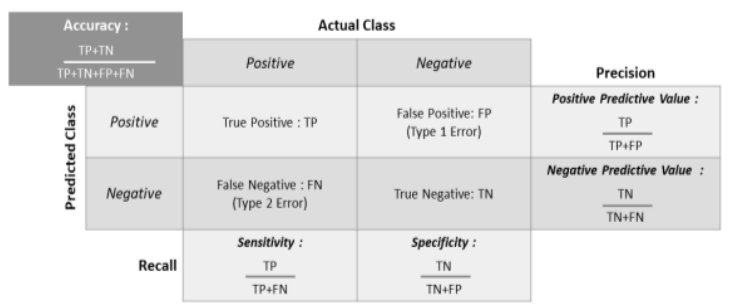

Fig. 6. The challenge of developing a culture of aggressive learning.

Fig. 6 presents the composition of the confusion matrix performance, which is composed of the actual class and the predicted class. An important benefit of the performance of the confusion matrix is the ability to determine the model's ability to predict results, such as the predictive ability or accuracy, model precision, model sensitivity, and model specificity (recall measurement). These values are used to determine the actual performance model. Moreover, Fig. 6 also demonstrates the formulas and methods for calculating the various performance parameters in detail.

\section{RESEARCH RESULTS AND DISCUSSIONS}

The research results classified the research report into five topics which are the data analysis results, modelling results, model testing results, model applying results, and summary of the significant factors.

\section{A. Data Analysis Results}

The sample set from the 463 samples was analyzed and summarized in Table II and Table III.

TABLE II: THE DATA COLLECTED COMPILED BY GENDER

\begin{tabular}{lccccc}
\hline \hline \multirow{5}{*}{ Gender } & \multicolumn{5}{c}{ Samples $(\mathrm{n}=463)$} \\
& Administrators & Lecturers & Staffs & Students & Total \\
& $(n 1)$ & $(n 2)$ & $(n 3)$ & $(n 4)$ & \\
\hline \multirow{2}{*}{ Male } & 4 & 27 & 13 & 141 & 185 \\
& $(0.86 \%)$ & $(5.83 \%)$ & $(2.81 \%)$ & $(30.45 \%)$ & $(39.96 \%)$ \\
Female & 3 & 41 & 13 & 221 & 278 \\
& $(0.65 \%)$ & $(8.86 \%)$ & $(2.81 \%)$ & $(47.73 \%)$ & $(60.04 \%)$ \\
Total: & 7 & 68 & 26 & 362 & 463 \\
& $(1.51 \%)$ & $(14.69 \%)$ & $(5.62 \%)$ & $(78.19 \%)$ & $(100 \%)$ \\
\hline \hline
\end{tabular}

Table II shows that the greatest number of respondents were the female, with 278 people representing 60.04 percent of all data providers.

TABLE III: THE DATA COLLECTED COMPILED BY AGE

$$
\text { Samples }(n=463)
$$

\begin{tabular}{lccccc}
\multicolumn{1}{c}{ Age } & Administrators & Lecturers & Staffs & Students & Total \\
& $(n 1)$ & $(n 2)$ & $(n 3)$ & $(n 4)$ & \\
\hline $20-30$ & 1 & 24 & 12 & 356 & 393 \\
years old & $(0.22 \%)$ & $(5.18 \%)$ & $(2.59 \%)$ & $(76.89 \%)$ & $(84.88 \%)$ \\
$31-40$ & 1 & 30 & 9 & 6 & 46 \\
years old & $(0.22 \%)$ & $(6.48 \%)$ & $(1.94 \%)$ & $(1.30 \%)$ & $(9.94 \%)$ \\
$41-50$ & 1 & 11 & 44 & 0 & 16 \\
years old & $(0.22 \%)$ & $(2.38 \%)$ & $(0.86 \%)$ & $(0.00 \%)$ & $(3.46 \%)$ \\
$51-60$ & 4 & 3 & 1 & 0 & 8 \\
years old & $(0.86 \%)$ & $(0.65 \%)$ & $(0.22 \%)$ & $(0.00 \%)$ & $(1.73 \%)$ \\
\multicolumn{1}{c}{ Total: } & 7 & 68 & 26 & 362 & 463 \\
& $(1.51 \%)$ & $(14.69 \%)$ & $(5.62 \%)$ & $(78.19 \%)$ & $(100 \%)$ \\
\hline \hline
\end{tabular}

Table III shows that the majority of data providers were between the ages of 20-30, with 393 people representing 84.88 percent of all data providers.
TABLE IV: THE DATA COLLECTED COMPILED BY EDUCATION

$$
\text { Samples }(n=463)
$$

\begin{tabular}{cccccc} 
Education & Administrators & Lecturers & Staffs & Students & Total \\
& $(n 1)$ & $(n 2)$ & $(n 3)$ & $(n 4)$ & \\
\hline \multirow{2}{*}{ Doctorate } & 6 & 9 & 0 & 0 & 15 \\
& $(1.30 \%)$ & $(1.94 \%)$ & $(0.00 \%)$ & $(0.00 \%)$ & $(3.24 \%)$ \\
Master & 1 & 55 & 14 & 6 & 76 \\
& $(0.22 \%)$ & $(11.88 \%)$ & $(3.02 \%)$ & $(1.30 \%)$ & $(16.41 \%)$ \\
Bachelor & 0 & 4 & 12 & 356 & 372 \\
& $(0.00 \%)$ & $(0.86 \%)$ & $(2.59 \%)$ & $(76.89 \%)$ & $(80.35 \%)$ \\
Total: & 7 & 68 & 26 & 362 & 463 \\
& $(1.51 \%)$ & $(14.69 \%)$ & $(5.62 \%)$ & $(78.19 \%)$ & $(100 \%)$ \\
\hline \hline
\end{tabular}

Table IV shows that the majority of the data providers have a bachelor's degree, with 372 people representing 80.35 percent of all data providers.

\begin{tabular}{|c|c|c|c|c|c|c|}
\hline \multirow{2}{*}{ Stages } & \multicolumn{6}{|c|}{ Satisfaction and Acceptance $(n=463)$} \\
\hline & $n 1$ & $n 2$ & $n 3$ & $n 4$ & Total Mean & Total S.D. \\
\hline \multicolumn{7}{|c|}{ Stage 1: Organization } \\
\hline Stage 1.1 & 3.71 & 2.87 & 3.04 & 3.69 & 3.53 & 1.12 \\
\hline Stage 1.2 & 3.86 & 3.43 & 3.39 & 3.98 & 3.86 & 0.92 \\
\hline Stage 1.3 & 3.57 & 3.57 & 3.42 & 3.96 & 3.87 & 0.87 \\
\hline Stage 1.4 & 4.42 & 4.24 & 3.89 & 4.16 & 4.16 & 0.82 \\
\hline Average & 3.89 & 3.53 & 3.44 & 3.95 & 3.86 & 0.93 \\
\hline \multicolumn{7}{|c|}{ Stage 2: Researcher } \\
\hline Stage 2.1 & 4.29 & 3.77 & 3.65 & 4.06 & 4.00 & 0.82 \\
\hline Stage 2.2 & 4.00 & 4.10 & 4.08 & 4.17 & 4.15 & 0.78 \\
\hline Stage 2.3 & 4.27 & 4.04 & 4.12 & 4.17 & 4.15 & 0.85 \\
\hline Average & 4.19 & 3.97 & 3.95 & 4.13 & 4.10 & 0.82 \\
\hline \multicolumn{7}{|c|}{ Stage 3: Students } \\
\hline Stage 3.1 & 3.86 & 3.88 & 3.58 & 4.03 & 3.98 & 0.93 \\
\hline Stage 3.2 & 3.71 & 3.50 & 3.39 & 3.91 & 3.82 & 0.89 \\
\hline Stage 3.3 & 3.71 & 3.37 & 3.35 & 3.96 & 3.84 & 0.89 \\
\hline Average & 3.76 & 3.58 & 3.44 & 3.97 & 3.88 & 0.90 \\
\hline \multicolumn{7}{|c|}{ Stage 4: Project Support } \\
\hline Stage 4.1 & 4.86 & 4.75 & 4.58 & 4.27 & 4.37 & 0.93 \\
\hline Stage 4.2 & 4.71 & 4.71 & 4.65 & 4.30 & 4.38 & 0.85 \\
\hline Stage 4.3 & 4.43 & 4.71 & 4.54 & 4.36 & 4.42 & 0.83 \\
\hline Average & 4.67 & 4.72 & 4.59 & 4.31 & 4.39 & 0.87 \\
\hline $\begin{array}{r}\text { Total } \\
\text { Average }\end{array}$ & 4.11 & 3.92 & 3.82 & 4.08 & 4.04 & 0.88 \\
\hline
\end{tabular}

TABLE V: SATISFACTION AND ACCEPTANCE TOWARD THE FACTORS

From Table $\mathrm{V}$ the analysis of the overall level of satisfaction and acceptance of factors, it was found that the overall level is at a high level of agreement (mean $=4.04$, S.D. $=0.88$ ). Moreover, the level of satisfaction with the project is the highest $($ mean $=4.39$, S.D. $=0.87)$. Therefore, it can be concluded that the respondents agreed and accepted the teaching and learning as a pilot project. In addition, the most attention toward the factors is the 4.3 budget support stage, which is the highest level of satisfaction (mean $=4.42$, S.D. $=$ 0.83 ). The second is the 4.2 staff support stage, which has a high level of satisfaction $($ mean $=4.38$, S.D. $=0.85)$. The lowest is the 1.1 organization policies stage, the level of satisfaction is at the middle level (mean = 3.53, S.D. $=1.12)$.

Interesting suggestions made were based on the budget which often gets delayed for transaction and sometimes insufficient in covering the overhead expenses. Researchers are not very interested with this issue because it is out of their control to manage appropriately and not worth the time for setting out the plans in conducting the research. Researchers who are truly interested in joining are few: most of them 
participate because it is part of their duties. There should be incentives to motivate participants and to develop research in the organization.

\section{B. Modelling Results}

Modelling results are the reports of the various models on different criteria, including the depth of the decision tree, and types of cross-validation method tests, which have different results as shown in Table VI.

TABLE VI: MODEL RESULTS FROM K-MEANS CLUSTERING

\begin{tabular}{|c|c|c|c|c|}
\hline \multirow{2}{*}{$\begin{array}{l}\text { Cluster } \\
\text { Number }\end{array}$} & \multirow{2}{*}{$\begin{array}{c}\text { Depth of } \\
\text { Decision Tree }\end{array}$} & \multicolumn{3}{|c|}{ Type of Cross-Validation Methods } \\
\hline & & 5-Fold & 10-Fold & Leave-one-out \\
\hline \multirow{7}{*}{ 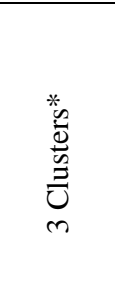 } & Level 3 & $90.51 \%$ & $92.21 \%$ & $92.66 \%$ \\
\hline & Level 4 & $95.91 \%$ & $95.88 \%$ & $96.33 \%$ \\
\hline & Level 5 & $95.90 \%$ & $96.53 \%$ & $96.98 \%$ \\
\hline & Level 6* & $96.12 \%$ & $96.75 \%$ & $98.06 \% *$ \\
\hline & Level 7 & $95.90 \%$ & $96.75 \%$ & $97.62 \%$ \\
\hline & Level 8 & $95.68 \%$ & $96.32 \%$ & $96.76 \%$ \\
\hline & Level 9 & $95.25 \%$ & $96.32 \%$ & $96.76 \%$ \\
\hline \multirow{7}{*}{ 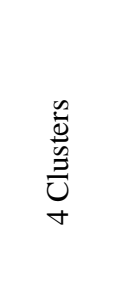 } & Level 3 & $71.30 \%$ & $76.01 \%$ & $81.21 \%$ \\
\hline & Level 4 & $87.25 \%$ & $86.63 \%$ & $82.51 \%$ \\
\hline & Level 5 & $88.33 \%$ & $89.00 \%$ & $84.88 \%$ \\
\hline & Level 6 & $89.62 \%$ & $89.65 \%$ & $86.83 \%$ \\
\hline & Level 7 & $89.41 \%$ & $90.09 \%$ & $88.12 \%$ \\
\hline & Level $8^{*}$ & $89.85 \%$ & $90.52 \% *$ & $88.12 \%$ \\
\hline & Level 9 & $90.28 \%$ & $90.51 \%$ & $89.20 \%$ \\
\hline \multirow{7}{*}{ 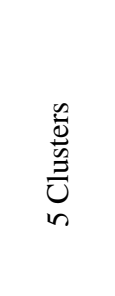 } & Level 3 & $61.99 \%$ & $61.97 \%$ & $61.12 \%$ \\
\hline & Level 4 & $77.73 \%$ & $78.83 \%$ & $81.64 \%$ \\
\hline & Level 5 & $87.69 \%$ & $87.25 \%$ & $85.96 \%$ \\
\hline & Level 6 & $87.04 \%$ & $87.90 \%$ & $85.53 \%$ \\
\hline & Level 7 & $87.70 \%$ & $88.33 \%$ & $87.26 \%$ \\
\hline & Level 8 & $88.78 \%$ & $86.83 \%$ & $87.26 \%$ \\
\hline & Level 9* & $89.21 \% *$ & $89.21 \% *$ & $87.69 \%$ \\
\hline
\end{tabular}

Table VI shows that the k-means model with the highest accuracy is the decision tree model that is classified into three clusters by dividing the model testing into the leave-one-out cross-validation method with a depth of six levels of the decision tree model, and has an accuracy of $98.06 \%$

However, the test results classified by other clusters yielded a lower accuracy. For example, the four clusters with the highest results are $90.52 \%$, and the five clusters have the highest results of $89.21 \%$.

\section{Model Testing Results}

From the results of the prototype model development, it can be concluded that the model with the highest accuracy is the development of the model from k-means clustering, with the appropriate number of 3 clusters, and the leave-one-out cross-validation has the result with an accuracy of $98.06 \%$. Details of the developed model are shown in Table VII.

\section{Model Applying Results}

From the model that has been selected and demonstrated on the performance, this section shows the decision tree model in Fig. 7 shown below. Furthermore, the decision tree rules for self-testing from the test results is shown in Table VIII, and the centroid of each cluster is shown in Table IX.
TABLE VII: THE MODEL TESTING RESUlTS

\begin{tabular}{|c|c|c|c|c|c|}
\hline \multirow{2}{*}{\multicolumn{2}{|c|}{$\begin{array}{l}\text { Accuracy: } 98.06 \% \\
\quad(+/-13.82 \%)\end{array}$}} & \multicolumn{3}{|c|}{ Actual Class } & \multirow{2}{*}{$\begin{array}{l}\text { Precision } \\
\text { Class }\end{array}$} \\
\hline & & $\begin{array}{c}\text { True } \\
\text { Cluster } 1\end{array}$ & $\begin{array}{c}\text { True } \\
\text { Cluster } 2\end{array}$ & $\begin{array}{c}\text { True } \\
\text { Cluster } 3\end{array}$ & \\
\hline \multirow{3}{*}{$\begin{array}{l}\tilde{y} \\
\tilde{U} \\
0 \\
0 \\
0 \\
.0 \\
0 \\
0 \\
0\end{array}$} & $\begin{array}{c}\text { Pred. } \\
\text { Cluster_l }\end{array}$ & 220 & 3 & 1 & $98.21 \%$ \\
\hline & $\begin{array}{c}\text { Pred. } \\
\text { Cluster_2 }\end{array}$ & 4 & 179 & 1 & $97.28 \%$ \\
\hline & $\begin{array}{c}\text { Pred. } \\
\text { Cluster_3 }\end{array}$ & 0 & 0 & 55 & $100.00 \%$ \\
\hline \multicolumn{2}{|c|}{ Recall Class } & $98.21 \%$ & $98.35 \%$ & $96.49 \%$ & \\
\hline
\end{tabular}

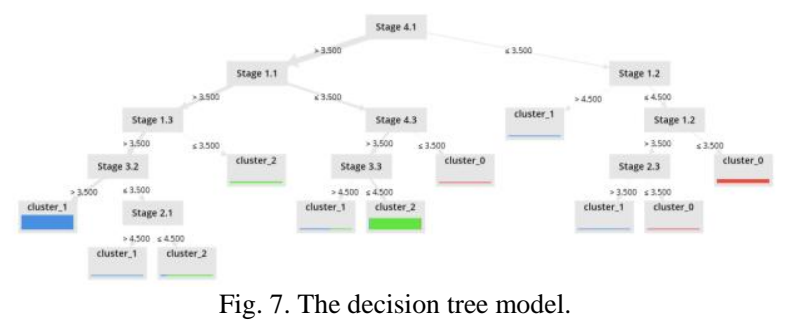

TABLE VIII: THE ARRANGEMENT OF CHANNELS

\begin{tabular}{|c|c|c|}
\hline Rule & Condition (If) & Prediction (Then) \\
\hline 2 & $\begin{array}{l}\text { If Stage } 4.1>3.500 \text { and Stage } \\
1.1>3.500 \text { and Stage } 1.3> \\
3.500 \text { and Stage } 3.2>3.500 \\
\text { If Stage } 4.1>3.500 \text { and Stage } \\
1.1>3.500 \text { and Stage } 1.3> \\
3.500 \text { and Stage } 3.2 \leq 3.500 \\
\text { and Stage } 2.1>4.500\end{array}$ & $\begin{array}{l}\text { Then, suitable for cluster_1 = } \\
99.52 \% \text {, and suitable for } \\
\text { cluster_2 }=0.48 \% \text {. } \\
\text { Then, suitable for cluster_1 = } \\
100 \% \text {. }\end{array}$ \\
\hline 3 & $\begin{array}{l}\text { If Stage } 4.1>3.500 \text { and Stage } \\
1.1>3.500 \text { and Stage } 1.3> \\
3.500 \text { and Stage } 3.2 \leq 3.500 \\
\text { and Stage } 2.1 \leq 4.500\end{array}$ & $\begin{array}{l}\text { Then, suitable for cluster_1 } 1= \\
12.50 \% \text {, and suitable for } \\
\text { cluster_2 }=87.50 \% \text {. }\end{array}$ \\
\hline 4 & $\begin{array}{l}\text { If Stage } 4.1>3.500 \text { and Stage } \\
1.1>3.500 \text { and Stage } 1.3 \leq \\
3.500\end{array}$ & $\begin{array}{l}\text { Then, suitable for cluster_2 }= \\
100 \% \text {. }\end{array}$ \\
\hline 5 & $\begin{array}{l}\text { If Stage } 4.1>3.500 \text { and Stage } \\
1.1 \leq 3.500 \text { and Stage } 4.3> \\
3.500 \text { and Stage } 3.3>4.500\end{array}$ & $\begin{array}{l}\text { Then, suitable for cluster_1 }= \\
60 \% \text {, and suitable for cluster_2 } \\
=40 \% \text {. }\end{array}$ \\
\hline 6 & $\begin{array}{l}\text { If Stage } 4.1>3.500 \text { and Stage } \\
1.1 \leq 3.500 \text { and Stage } 4.3> \\
3.500 \text { and Stage } 3.3 \leq 4.500\end{array}$ & $\begin{array}{l}\text { Then, suitable for cluster_1 = } \\
1.23 \% \text {, suitable for cluster_2 = } \\
98.15 \% \text {, and suitable for } \\
\text { cluster_3 }=0.62 \% \text {. }\end{array}$ \\
\hline 7 & $\begin{array}{l}\text { If Stage } 4.1>3.500 \text { and Stage } \\
1.1 \leq 3.500 \text { and Stage } 4.3 \leq \\
3.500\end{array}$ & $\begin{array}{l}\text { Then, suitable for cluster_3 = } \\
100 \% \text {. }\end{array}$ \\
\hline 8 & $\begin{array}{l}\text { If Stage } 4.1 \leq 3.500 \text { and Stage } \\
1.2>4.500\end{array}$ & $\begin{array}{l}\text { Then, suitable for cluster_1 = } \\
100 \% \text {. }\end{array}$ \\
\hline 9 & $\begin{array}{l}\text { If Stage } 4.1 \leq 3.500 \text { and Stage } \\
1.2 \leq 4.500 \text { and Stage } 1.2> \\
3.500 \text { and Stage } 2.3>3.500\end{array}$ & $\begin{array}{l}\text { Then, suitable for cluster_1 }= \\
100 \% \text {. }\end{array}$ \\
\hline 10 & $\begin{array}{l}\text { If Stage } 4.1 \leq 3.500 \text { and Stage } \\
1.2 \leq 4.500 \text { and Stage } 1.2> \\
3.500 \text { and Stage } 2.3 \leq 3.500\end{array}$ & $\begin{array}{l}\text { Then, suitable for cluster_3 }= \\
100 \% \text {. }\end{array}$ \\
\hline 11 & $\begin{array}{l}\text { If Stage } 4.1 \leq 3.500 \text { and Stage } \\
1.2 \leq 4.500 \text { and Stage } 1.2 \leq \\
3.500\end{array}$ & $\begin{array}{l}\text { Then, suitable for cluster_3 }= \\
100 \% \text {. }\end{array}$ \\
\hline \multicolumn{3}{|c|}{ Correct: 456 out of 463 training examples $(98.49 \%)$. } \\
\hline
\end{tabular}

\section{E. Summary of the Significant Factors}

From the data collection, there were 463 people who provided attitudes and satisfaction to the research. It can be concluded that the overall level of satisfaction is accepted $($ mean $=4.04$, S.D. $=0.88)$, as shown in Table V. Therefore, it can be concluded that the respondents agreed and accepted the teaching and learning as a pilot project.

In addition, the prototype model has been developed for predicting the highest accuracy levels $(98.06 \%)$ which is shown in Table VI and Table VII. Moreover, the results of 
the self-test data model are very accurate at the highest level, which is equal to $98.49 \%$ (Correct: 456 out of 463 training examples), as shown in Table VIII. Therefore, it can be concluded that this study was successful, as well as to assert that it can develop highly accurate models and also have high performance model testers.

TABLE IX: THE AVERAGE WITHIN CENTROID OF EACH CLUSTER

\begin{tabular}{cccc}
\hline \hline & $\begin{array}{c}\text { Stage and Cluster } \\
\text { Stages }\end{array}$ & & \\
Cluster_1 & Cluster_2 & Cluster_3 \\
\hline Stage 1. Organization 1.1 & 4.43 & 2.68 & 2.74 \\
Stage 1.2 & 4.49 & 3.49 & 2.60 \\
Stage 1.3 & 4.48 & 3.48 & 2.70 \\
Stage 1.4 & 4.43 & 4.24 & 2.81 \\
Stage 2. Researcher & & & \\
Stage 2.1 & 4.48 & 3.82 & 2.68 \\
Stage 2.2 & 4.45 & 4.19 & 2.84 \\
Stage 2.3 & 4.51 & 4.12 & 2.84 \\
Stage 3. Students & & & \\
Stage 3.1 & 4.50 & 3.70 & 2.86 \\
Stage 3.2 & 4.44 & 3.34 & 2.93 \\
Stage 3.3 & 4.49 & 3.34 & 2.88 \\
Stage 4.1 & & & \\
Stage 4.2 & 4.44 & 4.91 & 2.37 \\
Stage 4.3 & 4.41 & 4.87 & 2.74 \\
Stage 4.4 & 4.45 & 4.87 & 2.88 \\
\hline \hline & 4.44 & 4.91 & 2.37 \\
Total Number of Items: 463 & 224 items & 182 items & 57 items \\
\hline
\end{tabular}

Finally, the significant factors from this research are composed of nine factors as follows: Stage 1.1 The policies of the organization, Stage 1.2 The vision of the organization, Stage 1.3 The mission of the organization, Stage 2.1 Experience and achievements of researchers, Stage 2.3 Qualifications of Research Team, Stage 3.2 Interest in the research topics, Stage 3.3 Impressions and examples in the past, Stage 4.1 Technology and laboratory support, and Stage 4.3 Budget support. From clustering and discovering these significant factors, the researcher can use the research results to develop a program for advising advisors in a serious project course in order to effectively be matched up with students who have a common attitude.

\section{Conclusions}

The purpose of the research is to survey attitude and perception as collaboration between researchers and students to develop a clustering model for advisors and students, and to develop factors that are significant to predict the right match in the senior projects course. Data collection was done with a questionnaire consisting of 463 samples from 7 administrators, 68 lecturers, 26 staff and 362 students from two institutions: The Faculty of Information Technology, Rajabhat Mahasarakham University, Maha Sarakham, Thailand, and the School of Information and Communication Technology, University of Phayao, Phayao, Thailand. The research methodology was designed and divided into three sections: preparation, implementation, and conclusion as shown in Fig. 4.

The results of a collaborative attitude and perception survey between researchers and students are shown in Table
V. The result was that respondents have a high level of overall satisfaction $($ mean $=4.04$, S.D. $=0.88)$. Thus, it can be concluded that the respondents agreed and accepted the teaching and learning as a pilot project. The result is a clustering model development for matching advisors and students. The result is that the model has the highest level of accuracy $(98.06 \%)$ as shown in Table VI and Table VII. Moreover, the results of the self-test data model were very accurate at the highest level, which is equal to $98.49 \%$ (Correct: 456 out of 463 training examples) as shown in Table VIII.

The result is the development of factors that are significant to predict the right match in senior projects course. The result consisted of nine important factors, which are stage 1.1 the policies of the organization, stage 1.2 the vision of the organization, stage 1.3 the mission of the organization, stage 2.1 experience and achievements of researchers, stage 2.3 qualifications of research team, stage 3.2 interest in the research topics, stage 3.3 Impressions and examples in the past, stage 4.1 technology and laboratory support, and stage 4.3 budget support. The researchers concluded that this research achieved its objectives with four machine learning tools and data mining techniques: k-means, decision tree, cross-validation methods, and confusion matrix. For future research projects, the researchers are committed to carrying out the study on the development of learners' achievement and aims to promote a learning culture based on the results and active learning of educational institutions.

\section{CONFLICT OF INTEREST}

The authors declare no conflict of interest.

\section{AUTHOR CONTRIBUTIONS}

Wongpanya Nuankaew and Sittichai Bussaman designed the research problems and research framework; Wongpanya Nuankaew and Pratya Nuankaew collected the data from the Huaima Wittayakom School, in Phrae Province of Thailand; Pratya Nuankaew and Direk Teeraputon analyzed the data and constructed the clustering models; Pratya Nuankaew wrote the paper and all authors had approved the final version; Pratya Nuankaew is responsible for communicating and delivering the research for journal publication.

\section{ACKNOWLEDGMENT}

This research is supported by the two organizations: the Rajabhat Mahasarakham University, Maha Sarakham, Thailand, and the University of Phayao, Phayao, Thailand. The researchers would like to thank the advisor, lecturers, students, technicians, and all respondents for their entire support.

\section{REFERENCES}

[1] M. Li et al., "Promoting reading comprehension and critical-analytic thinking: A comparison of three approaches with fourth and fifth graders," Contemporary Educational Psychology, vol. 46, pp. 101-115, Jul. 2016.

[2] P. Nuankaew and P. Temdee, "Determining of compatible different attributes for online mentoring model," in Proc. 2014 4th International Conference on Wireless Communications, Vehicular Technology, Information Theory and Aerospace Electronic Systems (VITAE), 2014, pp. 1-5. 
[3] P. Nuankaew and P. Temdee, "Of online community: Identifying mentor and mentee with compatible different attributes and decision tree," in Proc. 2015 12th International Conference on Electrical Engineering/ Electronics Computer, Telecommunications and Information Technology (ECTI-CON), 2015, pp. 1-6.

[4] W. Nuankaew, P. Nuankaew, and K. Phanniphong, "Lifelong learning application: Mobile application to promote lifelong learning and introduce educational institutions," Advances in Science, Technology and Engineering Systems Journal, vol. 2, no. 3, pp. 1556-1564, 2017.

[5] K. Pupara, W. Nuankaew, and P. Nuankaew, "An institution recommender system based on student context and educational institution in a mobile environment," in Proc. 2016 International Computer Science and Engineering Conference (ICSEC), 2016, pp. $1-6$.

[6] W. Sritong, S. Pisai, W. Nuankaew, and P. Nuankaew, "The development of monitoring application in the students' activities, Faculty of Information Technology, Rajabhat Mahasarakham University. (in Thai)," in Proc. 2017 the 5th ASEAN Undergraduate Conference in Computing (AUCC), 2017, pp. 1154-1157.

[7] W. Sritong et al., presented at ASEAN Undergraduate Conference in Computing (AUCC), 2017.

[8] D. Zampunieris, "Proactive e-learning management system," in Proc. Seventh IEEE International Conference on Advanced Learning Technologies (ICALT 2007), 2007, pp. 645-646.

[9] A. Ruiz-Iniesta, G. Jimenez-Diaz, and M. Gomez-Albarran, "Recommendation in repositories of learning objects: A proactive approach that exploits diversity and navigation-by-proposing," in Proc. 2009 Ninth IEEE International Conference on Advanced Learning Technologies, 2009, pp. 543-545.

[10] D. Gallego, E. Barra, S. Aguirre, and G. Huecas, "A model for generating proactive context-aware recommendations in e-Learning systems," in 2012 Frontiers in Education Conference Proceedings, 2012, pp. 1-6.

[11] M. Reuter et al., "Learning factories' trainings as an enabler of proactive workers' participation regarding industrie 4.0," Procedia Manufacturing, vol. 9, pp. 354-360, Jan. 2017.

[12] S. Moon and J. G. Carbonell, "Proactive learning with multiple class-sensitive labelers," in Proc. 2014 International Conference on Data Science and Advanced Analytics (DSAA), 2014, pp. 32-38.

[13] W. Tan, A. Tang, T. Wang, W. Tan, L. Li, and Z. Zhang, "An overall lifecycle modeling method for e-learning services and the cooperative mechanism based on PCDA," in Proc. 2013 IEEE International Conference on Systems, Man, and Cybernetics, 2013, pp. 669-674.

[14] D. A. Vidhate and P. Kulkarni, "Performance enhancement of cooperative learning algorithms by improved decision making for context based application," in Proc. 2016 International Conference on Automatic Control and Dynamic Optimization Techniques (ICACDOT), 2016, pp. 246-252.

[15] C. T. Chang, C. Y. Tsai, S. E. Peng, H. H. Tsai, and P. T. Yu, "On the design of multi-user streaming feedback system for application of cooperative learning," in Proc. 2016 International Computer Symposium (ICS), 2016, pp. 656-659.

[16] P. Maresca, E. Gómez, J. Caja, C. Barajas, and R. Ledesma, “Academic learning platform for practical classes: A learning model in manufacturing engineering," Procedia Engineering, vol. 132, pp. 205-212, Jan. 2015.

[17] A. Bouabid, P. Vidal, and J. Broisin, "Integrating learning management systems and practical learning activities: The case of computer and network experiments," in Proc. 2009 Ninth IEEE International Conference on Advanced Learning Technologies, 2009, pp. 398-402.

[18] A. Mathew, V. Pangracious, A. Varghese, A. Thomas, D. Mathew, and J. George, "PROJECT HAWK: An innovative introduction of practical learning and entrepreneurship in engineering education," in Proc. 2012 2nd Interdisciplinary Engineering Design Education Conference (IEDEC), 2012, pp. 34-40.
[19] A. Smith and C. Bluck, "Multiuser collaborative practical learning using packet tracer," in Proc. 2010 Sixth International Conference on Networking and Services, 2010, pp. 356-362.

[20] G. Hamerly and J. Drake, "Accelerating Lloyd's algorithm for k-means clustering," Partitional Clustering Algorithms, Springer, 2015, pp. 41-78.

[21] P. Nuankaew, W. Nuankaew, and P. Temdee, "Institution recommendation using relationship optimisation between program and student context," Int. J. High. Educ. Sustain., vol. 2, no. 4, pp. 279-302, 2019.

[22] P. Nuankaew, W. Nuankaew, K. Phanniphong, R. Fooprateepsiri, and S. Bussaman, "Analysis dropout situation of business computer students at University of Phayao," The Impact of the 4th Industrial Revolution on Engineering Education, Cham, 2020, pp. 419-432.

[23] P. Nuankaew, "Dropout situation of business computer students, University of Phayao," Int. J. Emerg. Technol. Learn. IJET, vol. 14, no. 19, pp. 115-131, Oct. 2019.

Copyright $\odot 2021$ by the authors. This is an open access article distributed under the Creative Commons Attribution License which permits unrestricted use, distribution, and reproduction in any medium, provided the original work is properly cited (CC BY 4.0).

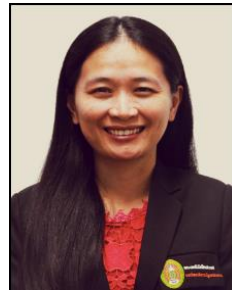

Wongpanya Nuankaew received a B.Sc. degree in computer science in 2004 , and the M.Sc. degree in information technology in 2007 from Naresuan University. She is currently a lecturer at the Faculty of Information Technology, Rajabhat Maha Sarakham University, Maha Sarakham, Thailand. Her research interests are in digital education, innovation and knowledge management, data science, and big data and information technology management.

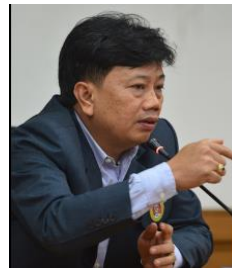

Sittichai Bussaman received his B.Sc. in statistic in 1990 from Srinakharinwirot University, the M.Sc. in computer science and information technology in 1997 from King Mongkut's Institute of Technology Ladkrabang and the Ph.D. in educational technology and communications in 2013 from Mahasarakham University. He is currently an associate professor at the Faculty of Science and Technology, Rajabhat Maha Sarakham University, Maha Sarakham, Thailand. His research interests are data mining in education, online learning, pattern recognition, and Artificial Intelligence.

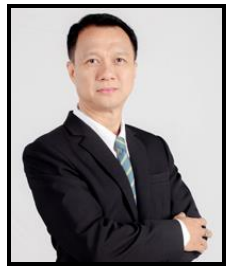

Direk Teeraputon received his B.Ed. in educational technology in 1991 from the Silpakorn University, the M.Ed. in audio-visual education in 1995 and the Ph.D. in educational technology and communication in 2004 from the Chulalongkorn University. He is currently a senior lecturer at Faculty of Education, Naresuan University, Thailand. His research interests are instruction system design, learning resources center management, distance education, self-regulated learning and training.

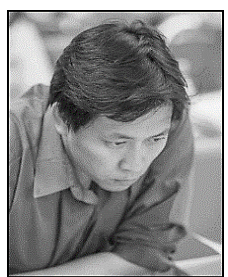

Pratya Nuankaew received a B.Ed. degree in educational technology in 2001, the M.Sc. degree in information technology in 2008 from Naresuan University, and a Ph.D. degree in computer engineering in 2018 from Mae Fah Luang University. $\mathrm{He}$ is currently a lecturer at the School of Information and Communication Technology, University of Phayao, Phayao, Thailand. His research interests are in online mentoring model, mentoring relationships, social network analysis, ubiquitous computing, learning analytics, digital education, and educational data mining. 